\title{
Kinetics of Indium Extraction from Mechanically Activated ITO Scrap
}

\author{
Xuanhai Li ${ }^{1}$, Yanjuan Zhang ${ }^{1}$, Jinhuan $\mathrm{Yao}^{2}$, Xiumin $\mathrm{Li}^{1}$, Liuping Pan ${ }^{1}$ \\ ${ }^{1}$ School of Chemistry and Chemical Engineering, Guangxi University, Nanning, China; ${ }^{2}$ Department of Material and Chemical En- \\ gineering, Guilin University of Technology, Guilin, China. \\ Email: xuanhli@gxu.edu.cn; xianquan919@163.com
}

Received February 23 ${ }^{\text {rd }}, 2011$; revised March $15^{\text {th }}, 2011$; accepted April $6^{\text {th }}, 2011$.

\begin{abstract}
The indium tin oxide scrap (ITOS) was mechanically activated by a stirring ball mill and subsequently studied for the leaching behavior and kinetics of extracting indium from ITOS in hydrochloric acid solution. The X-ray diffraction $(X R D)$ analysis showed that MA caused the decrease in crystalline phase and increase in lattice distortion. The effects of reaction temperature and hydrochloric acid concentration on the leaching rate of indium were also investigated, which showed that the indium extraction from ITOS had significant dependency on temperature and HCl concentration. The equal-recovery method was used for kinetics analysis. When ITOS was mechanically activated for 15 and $30 \mathrm{~min}$, the apparent activation energy decreased from $90.6 \mathrm{~kJ} / \mathrm{mol}$ to 70.3 and $53.0 \mathrm{~kJ} / \mathrm{mol}$, respectively, which indicated that MA could enhance the reactivity of ITOS and accelerated the reaction. The reaction orders of extracting indium from the nonactivated, milled for 15 and $30 \mathrm{~min}$ ITOS with respect to $\mathrm{HCl}$ concentration were $2.30,1.44$, and 1.31, respectively.
\end{abstract}

Keywords: ITO, Mechanical Activation, Indium, Leaching Kinetics

\section{Introduction}

As a rare metal, indium is widely used in many fields due to its quite unique physical and chemical properties $[1,2]$. In recent years, Most of the indium (about $70 \%$ ) is used to produce indium tin oxide (ITO), which plays an important role in optoelectronic devices, transparent electrodes for liquid crystal display and solar cells [3-6]. With the rapid increase in demand of liquid crystal display, the production of ITO becomes blooming. In the manufacture of transparent conduction oxide (TCO), only about $15 \%$ of ITO is consumed in making TCO, and the rest (85\%) becomes scrap [7]. In addition, some leftover material, smear metal and wasters are also produced during the production of ITO targets. Due to the increasing demand and over-exploitation, the resource of indium is gradually exhausted. So, it is very important to recover indium from indium-contained wastes. Current indium sources estimate that $65 \%$ of the indium from used ITO targets is recovered via reclaim processing. Therefore, it is of great importance to study the techniques of recycling indium from these wastes. In the production of ITO targets, different proportion of $\mathrm{In}_{2} \mathrm{O}_{3}$ and $\mathrm{SnO}_{2}$ forms different crystal structure phases under the high temperature and high pressure conditions. The difference in crystal structure leads to the difference in recycling indium from ITO scraps (ITOS). For some crystal phases, it is very difficult to be dissolved in acid solution. Therefore, the investigation of enhancing indium extraction from ITOS has great significance both in theory and practice.

Mechanical activation (MA) may increase the internal energy and reaction activity due to the formation of lattice distortion, the defect in crystal lattice, and amorphization in solid material via the mechanical force by high-energy milling [8-10]. In recent years, many researchers have investigated the effect of MA on hydrometallurgical extraction of valuable metals from minerals by using different methods and activation equipment, such as vibrating mill, planetary mill, and drum ball mill, showing that MA plays a positive role in the dissolution of minerals [11-13]. In this study, MA was used for the pretreatment of ITOS. The purpose of this work was to investigate the effects of MA on the change in crystal structure of ITOS and the kinetics of extracting indium from ITOS in hydrochloric acid. 


\section{Experimental}

\subsection{Materials}

The ITOS (containing $42.5 \%$ of indium), which was the acid leaching residue of waste ITO target, was selected as the raw material. The grain size distribution of the sample used for this study was narrow with the average diameter of $160.6 \mu \mathrm{m}$. The sample was characterized by $\mathrm{X}$-ray diffraction (XRD, Rigaku model D/max-2500) and the result is illustrated in Figure 1, which shows that indium tin oxide $\left(\mathrm{In}_{4} \mathrm{Sn}_{3} \mathrm{O}_{12}\right.$, PDF 88-0773) and aluminium phosphide (AIP, PDF 80-0013) were the main components in the ITOS.

\subsection{Mechanical Activation}

MA of ITOS samples was performed using a customized stirring mill driven by a commercial available drill press equipped with a speed-tuned motor. In each milling experiment, the stainless steel chamber $(1200 \mathrm{~mL})$ was filled with $10,000 \mathrm{~g}$ of $4 \mathrm{~mm}$-diameter stainless steel balls and $200 \mathrm{~g}$ of as-received ITOS, then the samples were subjected to dry milling under air atmosphere and no other additives were used during the milling. Mechanically activated ITOS samples were obtained after milled for 15 and $30 \mathrm{~min}$, and the activated samples were sealed for XRD analysis and leaching experiments.

\subsection{Leaching Experiment}

The leaching reactor was a $1000 \mathrm{~mL}$ three-neck flask, equipped with a mechanical stirrer, thermometer, reflux condenser and sampler and immersed in a thermostatically controlled water bath. In a typical experiment, the liquid-to-solid ratio and stirring speed were fixed as 66:1 $(\mathrm{mL} / \mathrm{g})$ and $700 \mathrm{rpm} .660 \mathrm{~mL}$ of hydrochloric acid solution was first added in the reactor for preheating. When the temperature reached the pre-set value, $10.0 \mathrm{~g}$ of sample was put into the reactor. At appropriate time intervals, solution samples of $2 \mathrm{~mL}$ were withdrawn and the indium concentration was determined by a polarographic analyzer (Model JP-303).

\section{Results and Discussion}

\subsection{Change of Crystal Structure}

Figure 2 shows the XRD patterns of nonactivated ITOS and samples milled for different time. It can be observed that the intensity of the main planes of ITO $(211,122$, $214,413)$ decreased with increasing the activation time, and the diffraction peaks broadened after MA. No new phase was found according to the XRD patterns of activated ITOS. The decrease in intensity of diffraction lines is the result of decrease in crystalline phase, and the broadening of X-ray diffraction line profile obtained in a

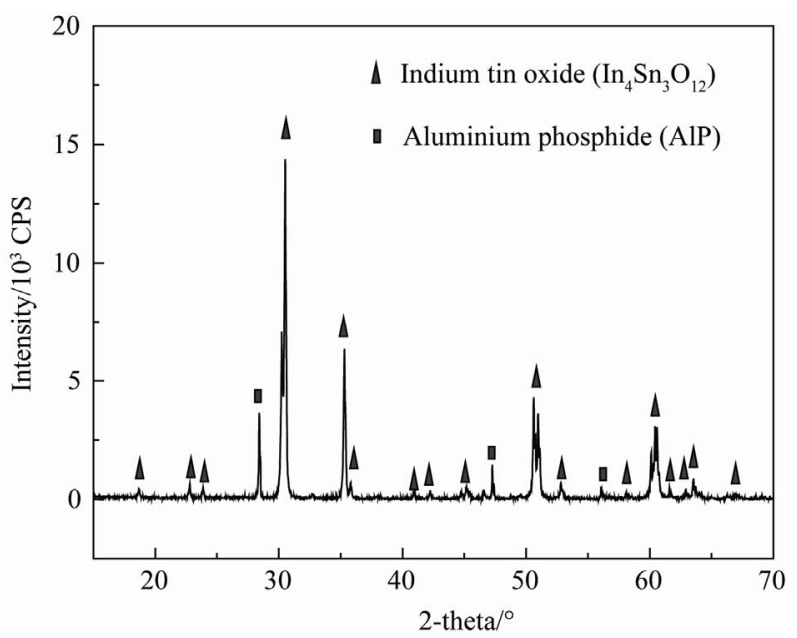

Figure 1. XRD pattern of the nonactivated ITOS.

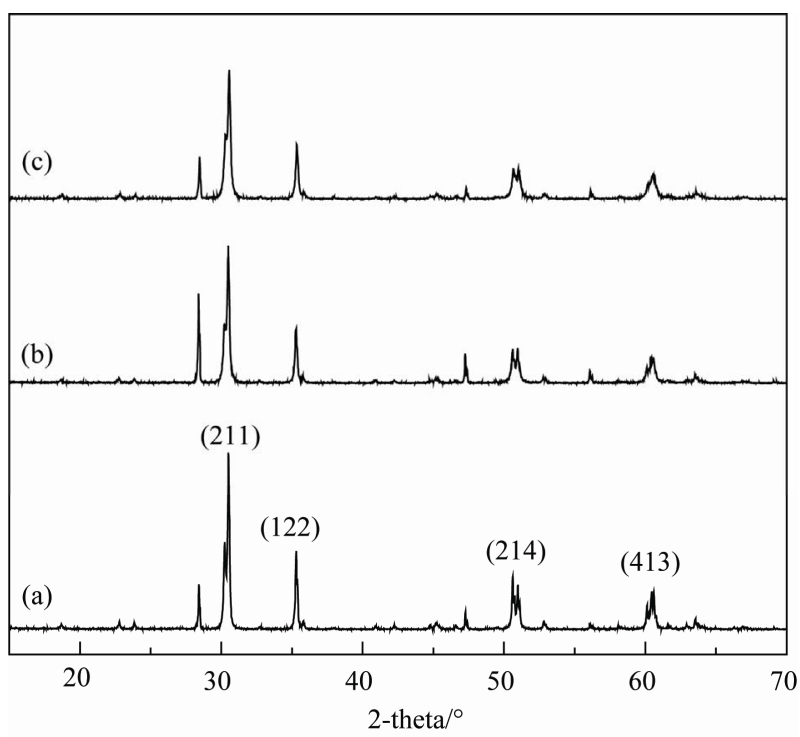

Figure 2. XRD patterns of the (a) nonactivated; (b) 15 min and (c) 30 min milled ITOS.

diffractometer attributes to instrumental and physical (crystallite size and lattice strain) factors [14]. So MA caused obvious changes in crystalline phase, crystallite size and lattice strain, which may subsequently enhance the chemical reactivity of ITOS in hydrochloric acid.

\subsection{Kinetics Modeling}

If the leaching rate is very fast at the initial stages of reaction and decreases with reaction time, the equal-recovery method is usually used for kinetics analysis [15]. The apparent activation energy Ea can be determined by the following equation:

$$
\Delta \ln t=\Delta(1 / T)(E \mathrm{a} / R)
$$

where $t$ is the leaching time, $R$ is the ideal gas constant, $T$ 
is reaction temperature. As a result, the plot of $\ln t$ to $1 / T$ can be drawn, and the slope of the line is $-E \mathrm{a} / R$ or $E \mathrm{a} / R$.

As to calculate the reaction order $n$ under the same kinetic conditions, the similar equation also can be obtained as follows:

$$
\Delta \ln t=-n \Delta \ln C_{0}
$$

where $C_{0}$ is the initial concentration of $\mathrm{HCl}(\mathrm{mol} / \mathrm{L})$.

Therefore, by constructing the plots of $\ln t$ versus $\ln C$, the reaction order can be determined.

\subsection{Calculation of Activation Energy}

The experiments of extracting indium from the nonactivated and milled ITOS samples were carried out with a temperature range of $50^{\circ} \mathrm{C}$ to $90^{\circ} \mathrm{C}$ in acid solution containing $5 \mathrm{~mol} / \mathrm{L} \mathrm{HCl}$. The results are shown in Figure 3, which indicates that indium extraction increases with the increase of reaction temperature for all these samples. So the dissolution of ITOS was quite sensitive to the reaction temperature.

According to Equation (1), the leaching time ( $t$ ) of extracting $10 \%, 15 \%$ and $20 \%$ of indium from nonactivated and activated ITOS at different temperature was obtained from Figure 3. Taking the nonactivated sample as an example, Figure 4 plotted the straight lines of $\ln t$ versus $1 / T$. From the slopes $(E \mathrm{a} / R)$ of the straight lines, the apparent activation energy of extracting indium from nonactivated ITOS was calculated to be $90.6 \mathrm{~kJ} / \mathrm{mol}$. Similarly, the activation energies of extracting indium from the samples activated for 15 and 30 min were determined to be 70.3 and $53.0 \mathrm{~kJ} / \mathrm{mol}$, respectively. The values of activation energy show that the process of extracting indium from ITOS was significantly influenced by reaction temperature and chemical reaction was the controlling step [16]. The activation energy decreased obviously after milling, which demonstrates that MA reduced the dependency of ITOS dissolution on temperature.

\subsection{Calculation of Reaction Order}

The influence of hydrochloric acid concentration on the indium leaching rate of unmilled and activated ITOS was examined in the range of 1.0 to $4.0 \mathrm{~mol} / \mathrm{L}$ with the temperature of $80^{\circ} \mathrm{C}$. The results, shown in Figure 5, indicate that the $\mathrm{HCl}$ concentration has significant effect on the indium extraction. The leaching rate of indium increased with increasing the $\mathrm{HCl}$ concentration. It is notable that the indium extraction of milled ITOS samples increased significantly with the increase in $\mathrm{HCl}$ concentration when lower than $3.0 \mathrm{~mol} / \mathrm{L}$, but the increasing trends became slow with the $\mathrm{HCl}$ concentration higher than $3.0 \mathrm{~mol} / \mathrm{L}$, especially the $30 \mathrm{~min}$ milled one.

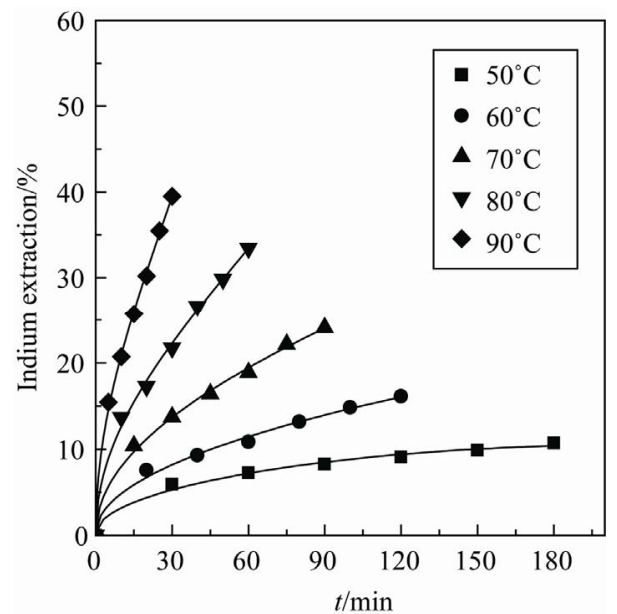

(a)

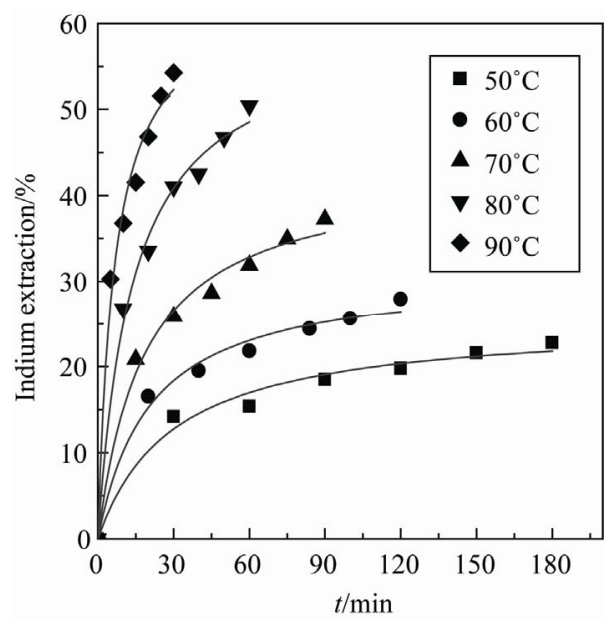

(b)

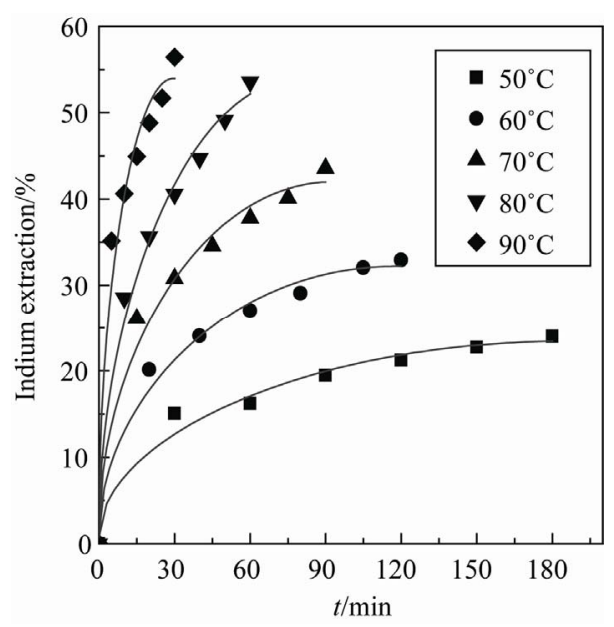

(c)

Figure 3. Effect of temperature on indium extraction from nonactivated and milled ITOS (5.0 M HCl; liquid-to-solid ratio: $66 \mathrm{~mL} / \mathrm{g}$; stirring speed: $700 \mathrm{rpm}$ ). (a) Nonactivated; (b) $15 \mathrm{~min}$; (c) $30 \mathrm{~min}$. 


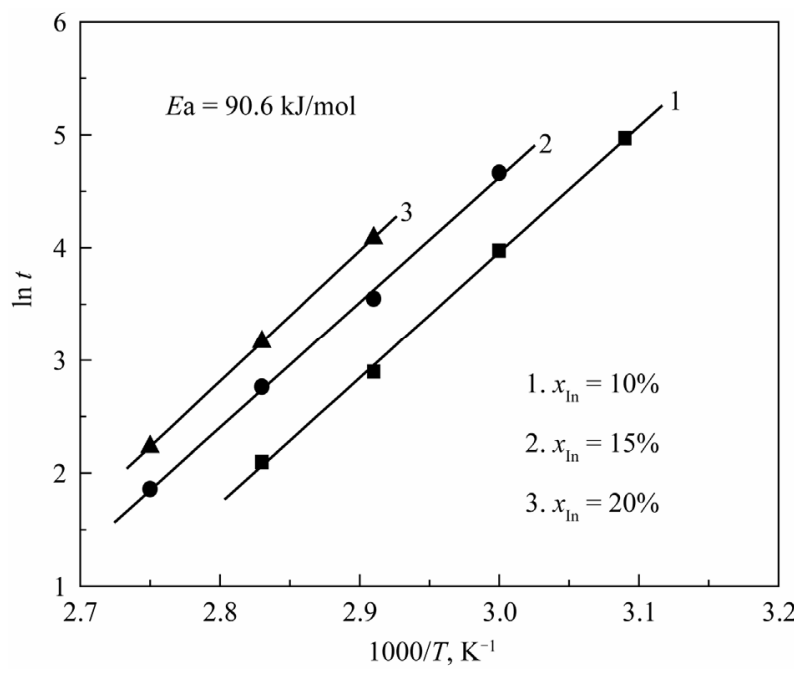

Figure 4. Arrhenius plot for extracting indium from nonactivated ITOS.

The use of the kinetic model also allows for the determination of the dependency of indium extraction on the concentration of $\mathrm{H}^{+}$ions. According to Equation (2), the leaching time of extracting $10 \%, 15 \%$ and $20 \%$ of indium from different ITOS samples at different $\mathrm{HCl}$ concentrate was obtained from Figure 5. Plots of $\ln t$ versus $\ln C_{\mathrm{HCl}}$ in Figure 6 were drawn for the nonactivated sample and exhibiting an excellent linear relationship. The reaction order of nonactivated ITOS dissolution with respect to $\mathrm{HCl}$ was proportional to 2.30 power of $\mathrm{HCl}$ concentration $\left([\mathrm{HCl}]^{2.30}\right)$. Similarly, the reaction orders for the indium extraction from 15 and 30 min milled samples were found proportional to 1.44 and 1.31 power of $\mathrm{HCl}$ concentration, respectively. The decrease in reaction order after milling indicates that MA could decrease the dependency of indium leaching from ITOS on $\mathrm{HCl}$ concentration.

\section{Conclusions}

The effects of MA on crystal structure, leaching behavior and kinetics of extracting indium from ITOS were investigated in this study. The results showed that MA caused the decrease in crystalline phase and increase in lattice distortion. The leaching experiments of unmilled and mechanically activated samples showed that MA enhanced the reactivity of ITOS and increased the leaching rate and kinetics. After milled for 15 and $30 \mathrm{~min}$, the apparent activation energy of extracting indium from ITOS decreased from $90.6 \mathrm{~kJ} / \mathrm{mol}$ to 70.3 and 53.0 $\mathrm{kJ} / \mathrm{mol}$, respectively, while the reaction order decreased from 2.30 to 1.44 and 1.31 , respectively. The decrease in activation energy and reaction order indicated that MA decreased the dependency of ITOS dissolution on temperature and initial concentration of hydrochloric acid.

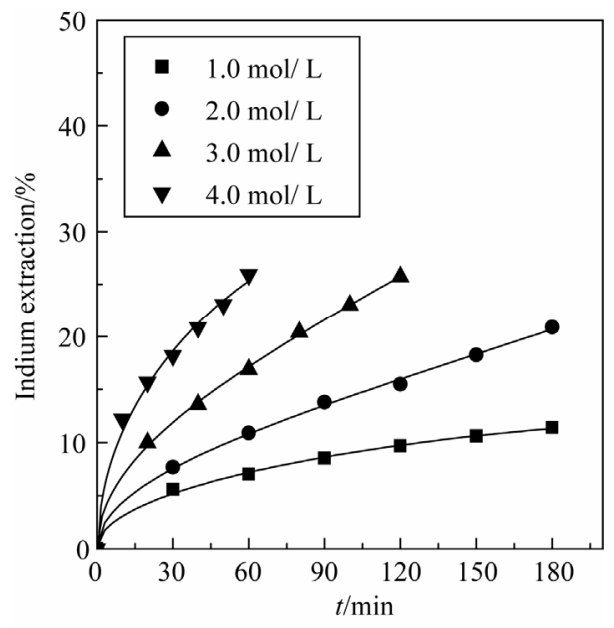

(a)

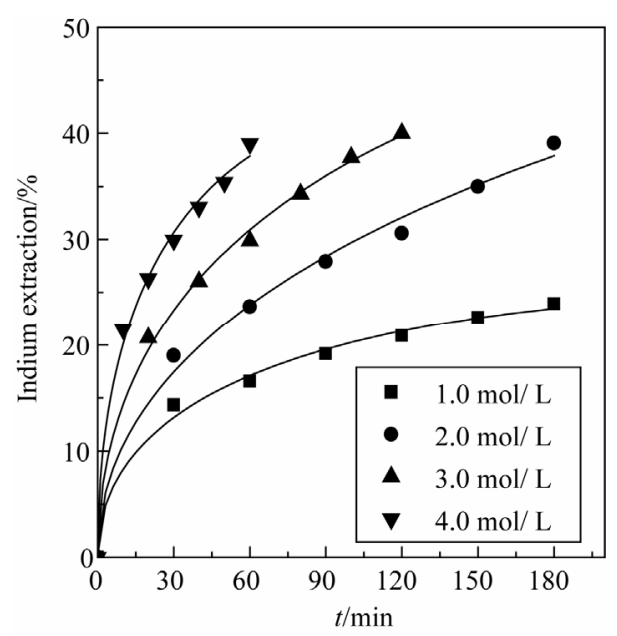

(b)

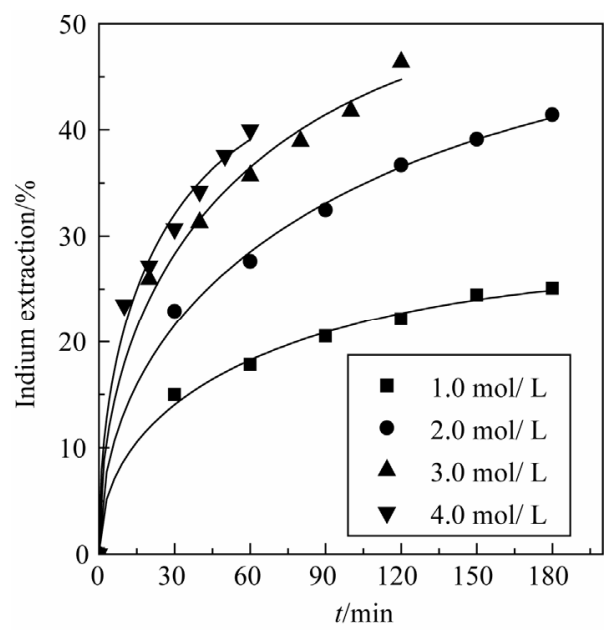

(c)

Figure 5. Effect of $\mathrm{HCl}$ concentration on indium extraction from nonactivated and milled ITOS (conditions as Figure 3). (a) Unactivated; (b) $15 \mathrm{~min}$; (c) $30 \mathrm{~min}$. 


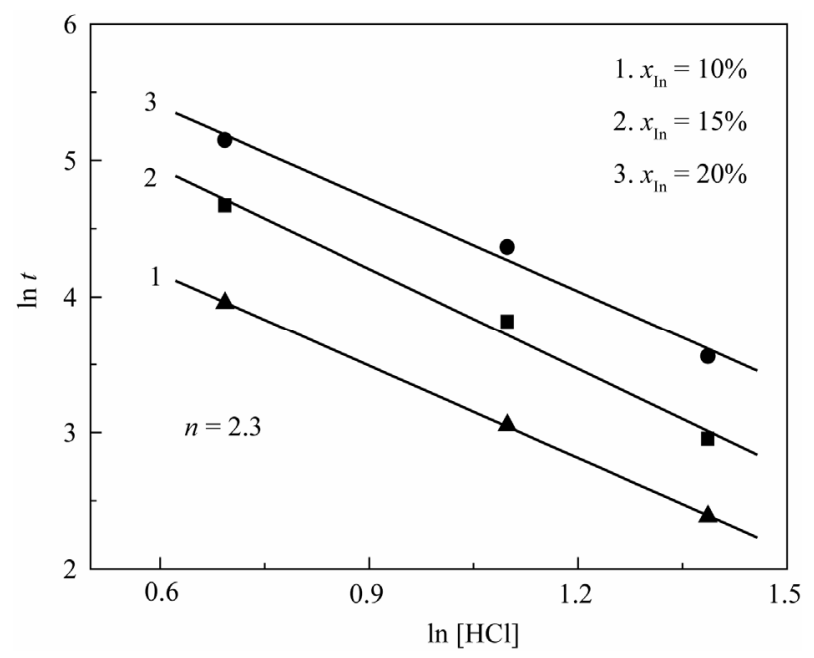

Figure 6. Determination of reaction order for extracting indium from nonactivated ITOS.

\section{Acknowledgements}

This work was financially supported by National Natural Science Foundation of China (No. 51064002) and Natural Science Foundation of Guangxi, China (No. 0728238).

\section{REFERENCES}

[1] A. M. Alfantazi and R. R. Moskalyk, "Processing of Indium: A Review," Minerals Engineering, Vol. 16, No. 8, 2003, pp. 687-694. doi:10.1016/S0892-6875(03)00168-7

[2] X. Tong, S. X. Song, J. He and A. Lopez-Valdivieso, "Flotation of Indium-Beard Marmatite from Multi-Metallic Ore," Rare Metals, Vol. 27, No. 2, 2008, pp. 107-111. doi:10.1016/S1001-0521(08)60096-0

[3] S. Calnan, H. M. Upadhyaya, M. J. Thwaites and A. N. Tiwari, "Properties of Indium Tin Oxide Films Deposited Using High Target Utilisation Sputtering," Thin Solid Films, Vol. 515, No. 15, 2007, pp. 6045-6050. doi:10.1016/j.tsf.2006.12.063

[4] A. B. Chebotareva, G. G. Untila, T. N. Kost, S. Jorgensen and A. G. Ulyashinc, "ITO Deposited by Pyrosol for Photovoltaic Applications," Thin Solid Films, Vol. 515, No. 24, 2007, pp. 8505-8510. doi:10.1016/j.tsf.2007.03.097

[5] J. Liu, D. Wu, N. Zhang and Y. Wang, "Effect of Surfactants on the Structure and Photoelectric Properties of ITO Films by Sol-Gel Method," Rare Metals, Vol. 29, No. 2, 2010, pp. 143-148. doi:10.1007/s12598-010-0025-3

[6] W. S. Jung, S. G. Yoon, S. M. Kang, S. Kim and D. H. Yoon, "Electrical and Optical Properties of ITO: Ca
Composite Thin Films for TEOLED Cathode," Thin Solid Films, Vol. 516, No. 16, 2008, pp. 5445-5448. doi:10.1016/j.tsf.2007.07.070

[7] S. Hsieh, C. Chen and W. C. Say, "Process for Recovery of Indium from ITO Scraps and Metallurgic Microstructures," Materials Science and Engineering B, Vol. 158, No. 1-3, 2009, pp. 82-87. doi:10.1016/j.mseb.2009.01.019

[8] C. Sasikumar, D. S. Rao, S. Srikanth, B. Ravikumar, N. K. Mukhopadhyay and S. P. Mehrotra, "Effect of Mechanical Activation on the Kinetics of Sulfuric Acid Leaching of Beach Sand Ilmenite from Orissa, India," Hydrometallurgy, Vol. 75, No. 1-4, 2004, pp. 189-204. doi:10.1016/j.hydromet.2004.08.001

[9] M. Achimovičová and P. Baláž, "Influence of Mechanical Activation on Selectivity of Acid Leaching of Arsenopyrite," Hydrometallurgy, Vol. 77, No. 1-2, 2005, pp. 3-7. doi:10.1016/j.hydromet.2004.09.008

[10] E. Godočíková, P. Baláž and E. Boldižárová, "Structural and Temperature Sensitivity of the Chloride Leaching of Copper, Lead and Zinc from a Mechanically Activated Complex Sulphide," Hydrometallurgy, Vol. 65, No. 1, 2002, pp. 83-93. doi:10.1016/S0304-386X(02)00094-4

[11] A. M. Amer, "Investigation of the Direct Hydrometallurgical Processing of Mechanically Activated Low-Grade Wolframite Concentrate," Hydrometallurgy, Vol. 58, No. 3, 2000, pp. 251-259. doi:10.1016/S0304-386X(00)00134-1

[12] P. Baláž, "Mechanical Activation in Hydrometallurgy," International Journal of Mineral Processing, Vol. 72, No. 1-4, 2003, pp. 341-354. doi:10.1016/S0301-7516(03)00109-1

[13] Y. J. Zhang, X. H. Li, L. P. Pan, Y. S. Wei and X. Y. Liang, "Effect of Mechanical Activation on the Kinetics of Extracting Indium from Indium-Bearing Zinc Ferrite," Hydrometallurgy, Vol. 102, No. 1-4, 2010, pp. 95-100. doi:10.1016/j.hydromet.2010.02.003

[14] R. Ebrahimi-Kahrizsangi, M. H. Abbasi and A. Saidi, "Mechanochemical Effects on the Molybdenite Roasting Kinetics," Chemical Engineering Journal, Vol. 121, No. 2-3, 2006, pp. 65-71. doi:10.1016/j.cej.2006.04.011

[15] Z. W. Zhao, G. Zhang, G. S. Huo and H. G. Li, "Kinetics of Atmospheric Leaching Molybdenum from Metalliferous Black Shales by Air Oxidation in Alkali Solution," Hydrometallurgy, Vol. 97, No. 3-4, 2009, pp. 233-236. doi:10.1016/j.hydromet.2009.02.004

[16] M. Ashraf, Z. I. Zafar and T. M. Ansari, "Selective Leaching Kinetics and Upgrading of Low-Grade Calcareous Phosphate Rock in Succinic Acid," Hydrometallurgy, Vol. 80, No. 4, 2005, pp. 286-292. doi:10.1016/j.hydromet.2005.09.001 